\title{
Rocket Wake Flow Interaction Testing in the Hot Plume Testing Facility (HPTF) Cologne
}

\author{
Daniel Kirchheck, Dominik Saile, and Ali Gülhan
}

\begin{abstract}
Rocket wake flows were under investigation within the Collaborative Research Centre SFB/TRR40 since the year 2009. The current paper summarizes the work conducted during its third and final funding period from 2017 to 2020. During that phase, focus was laid on establishing a new test environment at the German Aerospace Center (DLR) Cologne in order to improve the similarity of experimental rocket wake flow-jet interaction testing by utilizing hydrogen-oxygen combustion implemented into the wind tunnel model. The new facility was characterized during tests with the rocket combustor model HOC1 in static environment. The tests were conducted under relevant operating conditions to demonstrate the design's suitability. During the first wind tunnel tests, interaction of subsonic ambient flow at Mach 0.8 with a hot exhaust jet of approx. $920 \mathrm{~K}$ was compared to previously investigated cold plume interaction tests using pressurized air at ambient temperature. The comparison revealed significant differences in the dynamic response of the wake flow field on the different types of exhaust plume simulation.
\end{abstract}

Keywords Rocket wake-flows $\cdot$ Plume interaction $\cdot$ Hot plume testing

\section{Introduction}

During the ascent of a rocket launcher, the vehicle is exposed to constantly changing environmental conditions. Therefore, the loads imposed on the launch vehicle, in particular to the afterbody of launchers with a nozzle, subjected to the ambient flow, constantly change as well $[3,6,26]$. The afterbody flow of a rocket launcher is similar to that of an axisymmetric backward-facing step (BFS). In the mean, the flow around an axisymmetric BFS forms an annular recirculation region. It is enclosed by the rocket's base surface, the outer surface of the thrust nozzle and the shear

D. Kirchheck $(\bowtie) \cdot D$. Saile · A. Gülhan

Supersonic and Hypersonic Technology Department, Institute of Aerodynamics and Flow Technology, German Aerospace Center (DLR), 51147 Cologne, Germany

e-mail: daniel.kirchheck@dlr.de 
layers between the recirculation, the cold ambient flow and the hot exhaust stream. The recirculating base flow is also highly unsteady [4, 5, 23, 24, 31]. Instationary effects within this subsonic flow regime act on the surface of the nozzle and base plate, hence, they impose effects farther downstream on the jet shear layer. Thus, the structures in the base region are exposed to local pressure fluctuations and periodic loads.

\section{Related Activities within SFB/TRR40}

The investigation of such base flow phenomena on current and future space transportation vehicles with focus on the interaction of the ambient flow and the exhaust jet flow is one of the core research areas of the Collaborative Research Centre (SFB) Transregio 40 (TRR40) $[1,7,16]$. Previous publications indicate, that the buffet phenomenon, known to be the reason for prominent launcher failures (e.g. the Ariane 5 flight 157), is closely linked to the interaction flow field, especially for long nozzle structures with a length of more than one base diameter [3, 4, 8]. Nevertheless, until now, previous investigations were limited to cold-cold-interaction where the exhaust is modeled experimentally or numerically using moderately heated air or helium [25, 27, 29, 29].

Since the flow-flow-interaction is assumed to be significantly influenced by the dynamics of their inherent shear flow development, the relative flow velocity between the ambient and exhaust stream could be one of the most important influence factors for the combined wake flow characteristics. To address this influence on the resulting mechanical and thermal loads on the base and nozzle structure, an approach of enhanced similarity by using hot gas simulation with more realistic stagnation conditions and more realistic exhaust jet properties is followed in the present work.

For that, a newly built supply facility for gaseous hydrogen and oxygen (GH2/GO2) was added to the Vertical Wind Tunnel (VMK) of the German Aerospace Center (DLR) Cologne [9, 10, 12, 18]. Since that time, wind tunnel tests in the frame of $\mathrm{SFB} / \mathrm{TRR} 40$ incorporate a more realistic exhaust jet, which is generated by the combustion of a mixture of $\mathrm{GH} 2$ and $\mathrm{GO} 2$ within a combustion chamber inside the wind tunnel model. Prior to performing such wind tunnel tests, characterization of the new $\mathrm{GH} 2 / \mathrm{GO} 2$ supply facility, covering the targeted range of future operating conditions, was necessary [11].

\section{Motivation for Hot Plume Interaction Testing}

The resulting potential from an enhancement of the similarity of the exhaust jet's stagnation conditions and gas properties is pictured in Fig. 1. It is defined as the maximum nozzle exit velocity as a ratio between the experimental and flight values $u_{\text {max }}$ exp $/ u_{\text {max }}$,flight . Figure 1 shows its dependency on the combustion chamber temperature and the molecular mass of the exhaust gas. Both properties are closer to the real flight when using GH2/GO2 combustion instead of heated air or helium. Especially at a low oxidizer-fuel-ratio (OFR), the similarity of the maximum nozzle exit velocity is rather high, while thermal loads on the wind tunnel model are still manageable, due to low combustion chamber temperatures. Increasing OFR to flight relevant values of approx. 6 subsequently results in a similarity ratio close to one. 
Fig. 1 Similarity ratio (experiment over flight) of the maximum nozzle exit velocity, depending on the total temperature and composition of the exhaust gases; $\diamond: p_{\mathrm{cc}}=20.7 \mathrm{bar}$, $\square: p_{\mathrm{cc}}=68.9 \mathrm{bar}$

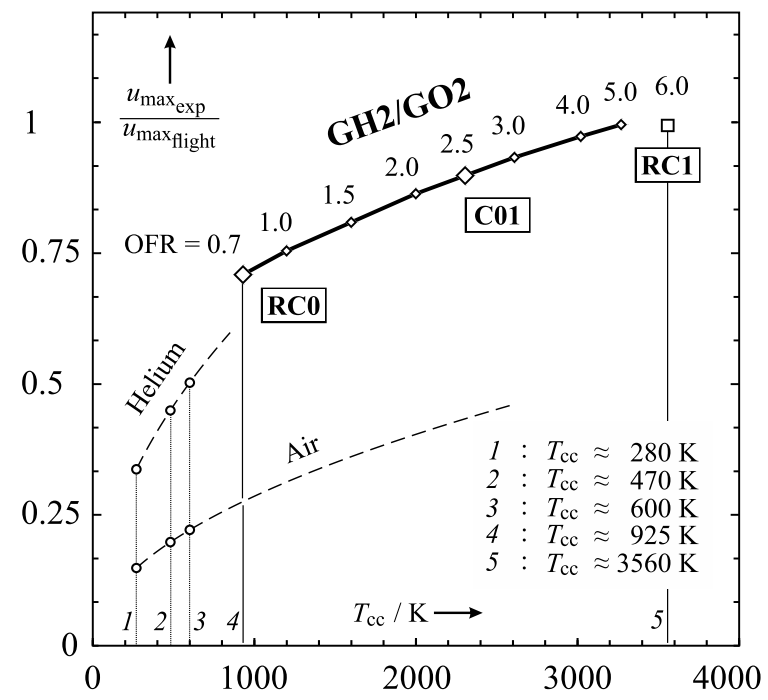

In the following, Sect. 2 gives an overview on this newly built facility, its implementation into the former wind tunnel test environment and its theoretical operating range. Section 3 refers to the activities of characterizing the facility operation after putting into service. They were conducted to prove the feasibility of the facility's concept for following wind tunnel test campaigns. In Sect. 4, first wind tunnel tests with hot plume interaction are presented and compared to cold plume interaction test cases, which were also investigated previously in [17, 20-22]. Finally, Sect. 5 concludes the main aspects of the work conducted within the third funding period of the SFB/TRR40 sub-project B1 and provides suggestions for further activities in that field.

\section{The Hot Plume Testing Facility (HPTF)}

The Hot Plume Testing Facility (HPTF) includes a combination of the Vertical Wind Tunnel Cologne (VMK), together with a supply facility for gaseous hydrogen (GH2) and gaseous oxygen (GO2) (Fig. 2).

The GH2/GO2 supply facility was built in the year 2017 to primarily serve for feeding wind tunnel models including integrated combustion chambers during wind tunnel testing. It was designed to the needs of the SFB/TRR40 sub-project B1, in which rocket wake flows, interacting with hot exhaust jets, were to be investigated providing more realistic jet composition and jet stagnation conditions. 


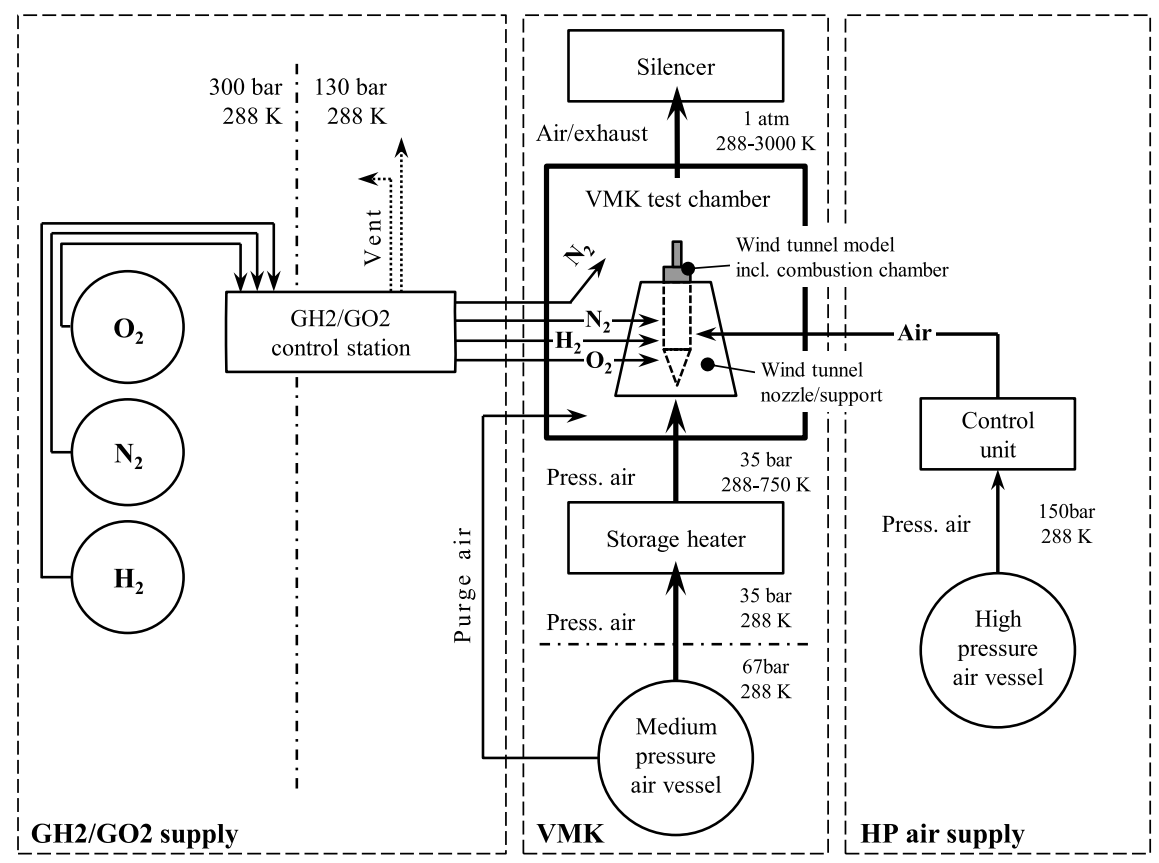

Fig. 2 The Hot Plume Testing Facility (HPTF), consisting of the Vertical Wind Tunnel Facility (VMK), the GH2/GO2 supply facility, and a high-pressure (HP) air supply system

\subsection{Vertical Wind Tunnel Cologne (VMK)}

The VMK, as one of the main components of HPTF, is a blow-down type wind tunnel with an atmospheric free stream test section in vertical alignment. The maximum operating pressure is 35 bar, which is maintained by a pressure reservoir of 1,000 cubic meters volume at a maximum pressure of 67 bar. The reservoir allows typical test durations of 30-60 s and the upstream heat storage can heat-up the flow up to $750 \mathrm{~K}$, which enables testing at ground-level conditions up to a Mach number of 2.8. The flow Mach number is set by various discrete nozzles in the supersonic range up to Mach 3.2. Subsonic conditions are set by a convergent nozzle of $340 \mathrm{~mm}$ exit diameter. The model extension is held by a central upstream support, which is integrated into the low-speed section of the subsonic nozzle and followed by two planes of metallic filter screens. The design of the test chamber is explosion proof and in combination with modern gas monitoring devices, explosion protected electric installations, and gas proof interfaces suitable for the operation of combustion tests with gaseous and solid propellant combinations. For the cold gas interaction tests, a high-pressure $(H P)$ dried air supply is available with a maximum supply pressure of 150 bar. 


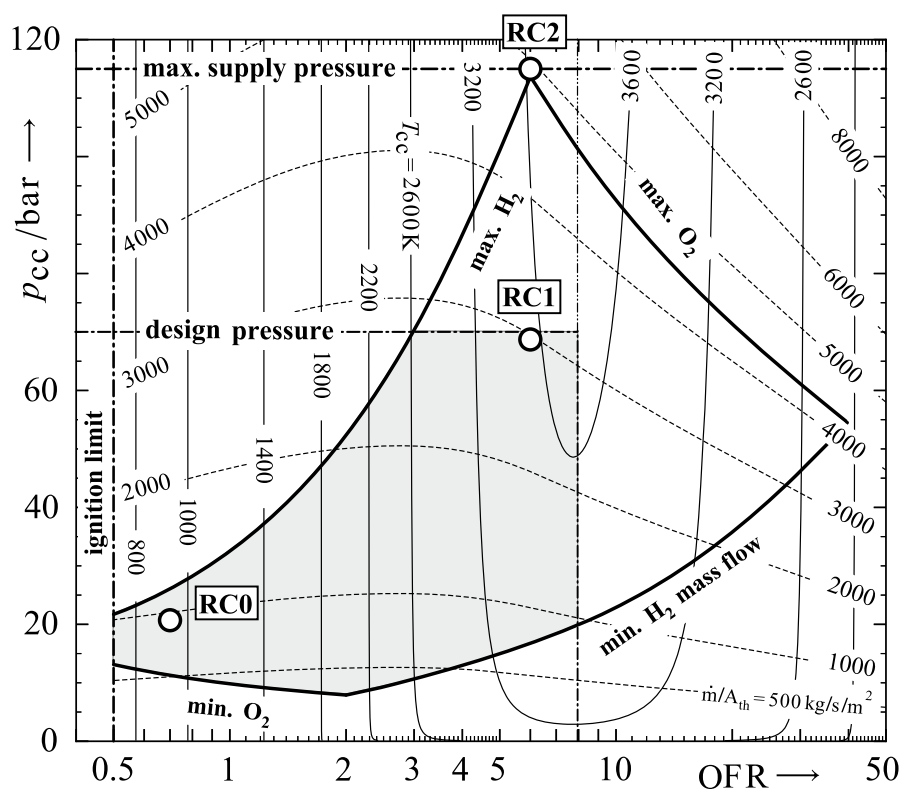

Fig. 3 Operating range of the GH2/GO2 supply facility in the field of total chamber pressure $p_{\mathrm{cc}}$ and oxidizer-fuel-ratio OFR as maximum operating envelope (thick solid line) and model design envelope (filled area) with design reference conditions $\mathrm{RC} 0, \mathrm{RC} 1$, and $\mathrm{RC} 2$

\subsection{GH2/GO2 Supply Facility}

The GH2/GO2 supply facility is an extension of the VMK infrastructure, which is designed especially for the hot gas investigations in the VMK test environment. It consists of a 300 bar gas storage for the supply with process gases (hydrogen, oxygen, and nitrogen for purging and inerting purposes) and a control station to set the operating conditions by an integrated mass flow controller. The control station operates at 130 bar and feeds the model combustor with a maximum of $399 \mathrm{~g} / \mathrm{s}$ oxygen and $67 \mathrm{~g} / \mathrm{s}$ hydrogen at a maximum chamber pressure of $115 \mathrm{bar}$.

The resulting operating range is given as a function of the chamber pressure $p_{\mathrm{cc}}$ and oxidizer-fuel-ratio OFR in Fig. 3. The theoretical chamber temperature $T_{\mathrm{cc}}$ (solid lines) and the area specific mass flow rate $\dot{m} / A_{\text {th }}$ (dashed lines) of the operating range are shown as iso-contours. The theoretical maximum operating envelope (thick line) and the model design envelope (filled area) are given by the maximum supply pressure/model design pressure, min/max mass flow rates, the theoretical ignition limit at OFR $>0.5$, and the maximum mass flow ratio OFR $<\mathrm{OFR}_{\mathrm{st}}=7.918$.

The reference configurations $\mathrm{RC} 0, \mathrm{RC} 1$, and $\mathrm{RC} 2$ were the drivers for the design process for the simulation of rocket propulsion applications, where the Ariane 5 main engine, Vulcain 2, was taken as flight reference. While for RC0, mechanical and thermal loads on the test models are relatively low, which enables a higher level of 
instrumentation and more detailed comparison with parallel numerical investigations, reference configuration $\mathrm{RC} 1$ already results in an excellent similarity of the exit velocity. Here, the reduced chamber pressure, compared to the maximum condition $\mathrm{RC} 2$, which is comparable to realistic engine properties, limits the possibility of duplicating both, the nozzle exit Mach number and a proper plume topology. In both cases, the high temperature and pressure introduce challenging model design and operation requirements.

\section{Characterization of HPTF for Wind Tunnel Testing}

Prior to performing wind tunnel tests, a characterization of the new GH2/GO2 supply facility $[9,18]$, covering the targeted range of future operating conditions within the model design envelope (Fig. 3) is needed. For that, a robust and flexible preliminary test combustor was introduced [10, 19]. Its modular design enables the qualification of materials and operating principles for a sophisticated development of the wind tunnel model including the combustion chamber. After entry into facility operation [10], preliminary tests were performed at the targeted reference conditions to validate the chamber and injector concept for further wind tunnel testing.

\subsection{HPTF Characterization Test Setup}

The test combustor for tests without ambient flow was integrated into the test chamber of VMK and fed by the GH2/GO2 supply facility (Fig. 4). It is a stand-alone combustor, the Hydrogen Oxygen Combustor 1 (HOCl), which is derived from literature in order to take advantage of published knowledge and to open up a range of comparative studies [15]. It uses a modular design, where the chamber modules, equipped with either temperature sensors, pressure sensors or a spark ignitor can be arranged in different order. The injector is a single element coaxial shear injector, which is replaceable to allow for quick modification of the injector geometry. For the nozzle part, different material concepts, like copper, molybdenum, and combinations with graphite inlays are available. The combustor is equipped with a high-frequency pressure transducer at the base plate of the combustion chamber, as well as 18 thermocouples, flush-mounted to the inner chamber wall and equally spaced along the axial direction.

\subsection{HPTF Characterization Test Results}

The GH2/GO2 supply, equipped with the HOC1 combustor, was mainly characterized for its performance at standard reference condition $\mathrm{RC} 0$, which was the main 

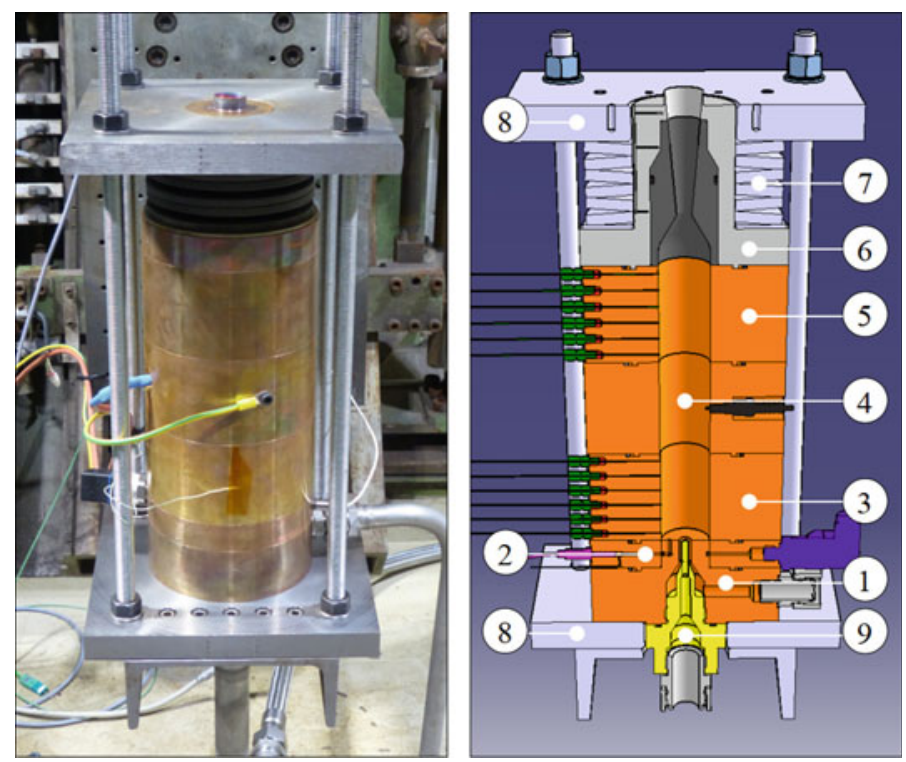

Fig. 4 Photograph and 3D sectional view of the model combustor HOC1; 1 injector body, 2 pressure port, 3 wall temperature measurement module, 4 ignition module, 5 wall temperature measurement module, 6 nozzle assembly, 7 strain compensation elements, 8 support plates, 9 coaxial injector element

operating condition for the following wind tunnel test campaign and additional tests at injector off-design conditions.

\section{Performance at Standard Reference Condition (RCO)}

The operation at RC0 was characterized to evaluate the control algorithms and accuracy of the input mass flows, as well as the major output parameters of the combustor. The primary input mass flows of hydrogen and oxygen $\left(\dot{m}_{\mathrm{H}_{2}}, \dot{m}_{\mathrm{O}_{2}}\right)$ are found to be within $\pm 1 \%$ and $\pm 3 \%$ of the set-point values after 6 s run time. A repeatability study (Fig. 5a and b) shows a relative standard deviation of $1.3 \%$ at $t=5 \mathrm{~s}$ down to $0.2 \%$ at $t=30 \mathrm{~s}$ for the mean chamber pressure. The peak-peak pressure amplitude $p_{\mathrm{cc}}^{\prime} \mathrm{p}$-p is averaged to 1.75 bar $( \pm 3.9 \%)$, which is called smooth combustion according to [30]. Figure 6 shows that the main contribution to the fluctuations originates from a screeching tone at approx. $3450 \mathrm{~Hz}$, which complies with the first natural longitudinal chamber mode (L1) [2].

\section{Performance at Off-design Conditions}

Several tests were carried out in order to investigate combustion roughness and low frequency stability, related to the propellant feed system. A variation of the oxidizer-fuel-ratio was performed at constant injector geometry between ratios of $0.7-2.5$ (Fig. 7, RC0 $\rightarrow$ C01). The relative fluctuation amplitude increases with OFR from \pm 3.1 to $\pm 8.9 \%$. Cases with OFR $<2$ showed smooth combustion. Similar tests 
a)

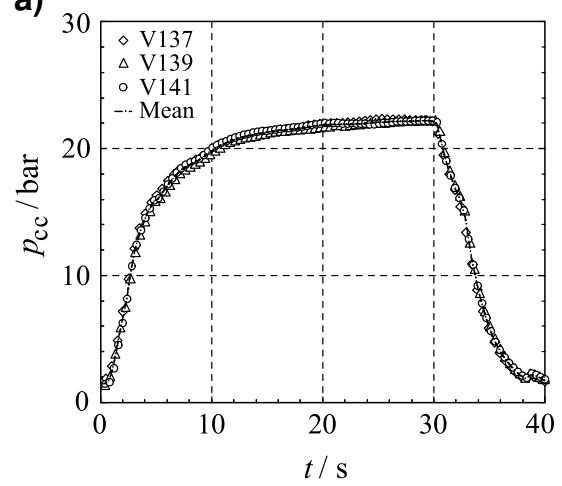

b)

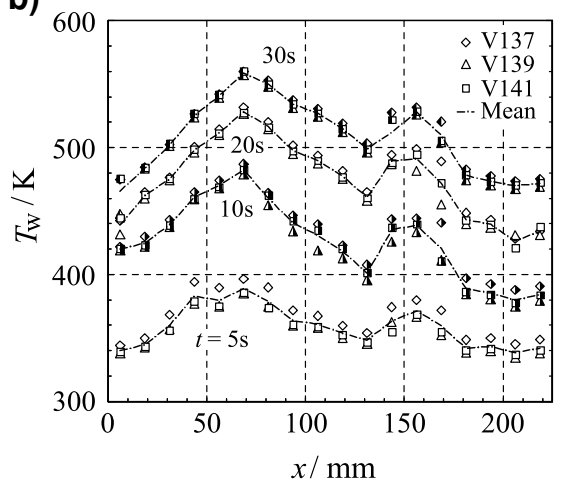

Fig. 5 a Repeatability study of combustion chamber pressure for three consecutive runs at standard reference condition $\mathrm{RC} 0$. b Repeatability study of combustion chamber wall temperature for three consecutive runs at standard reference condition $\mathrm{RC} 0$

Fig. 6 Spectogram of the combustion chamber pressure fluctuations at standard reference condition $\mathrm{RC} 0$; the first longitudinal mode (L1) is estimated as $f_{\mathrm{L} 1}=3,450 \mathrm{~Hz}$

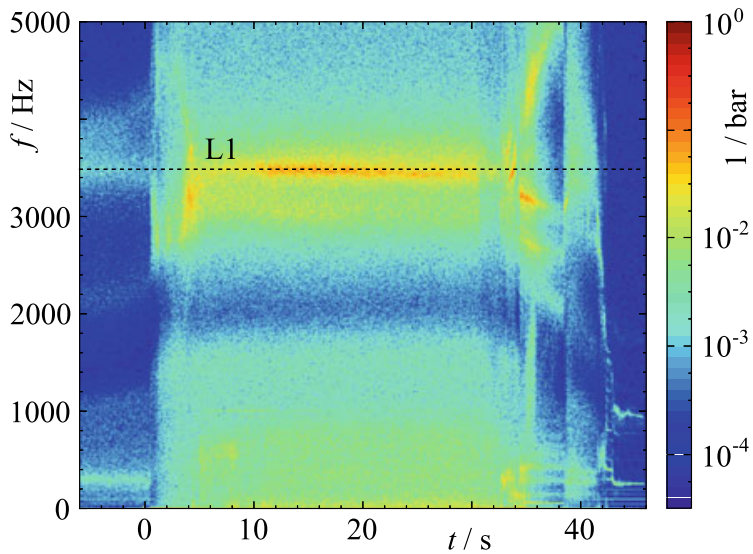

were run with a variation of the total mass flow rate up to a pressure of 60 bar (Fig. 7 , $\mathrm{RC} 0 \rightarrow \mathrm{RC} 1)$. The resulting fluctuation amplitude increases strongly up to $\pm 8.9 \%$ at rough but stable combustion. Hence, the operating range of the current injector, which was designed for reference condition $\mathrm{RC} 0$, providing smooth combustion with $p_{\mathrm{cc}}^{\prime \mathrm{p}-\mathrm{p}}< \pm 5.0 \%$ was found as $0.6<$ OFR $<2.0$ at $\dot{m}<150 \mathrm{~g} / \mathrm{s}$ (Fig. 7, filled area).

\section{Cold and Hot Plume Interaction Testing}

To investigate rocket base flow dynamics with regard to flow-flow-interaction between the ambient free stream and the propulsive jet, also referred to as the external and internal flows, the test object, an axisymmetric wind tunnel model, was located 


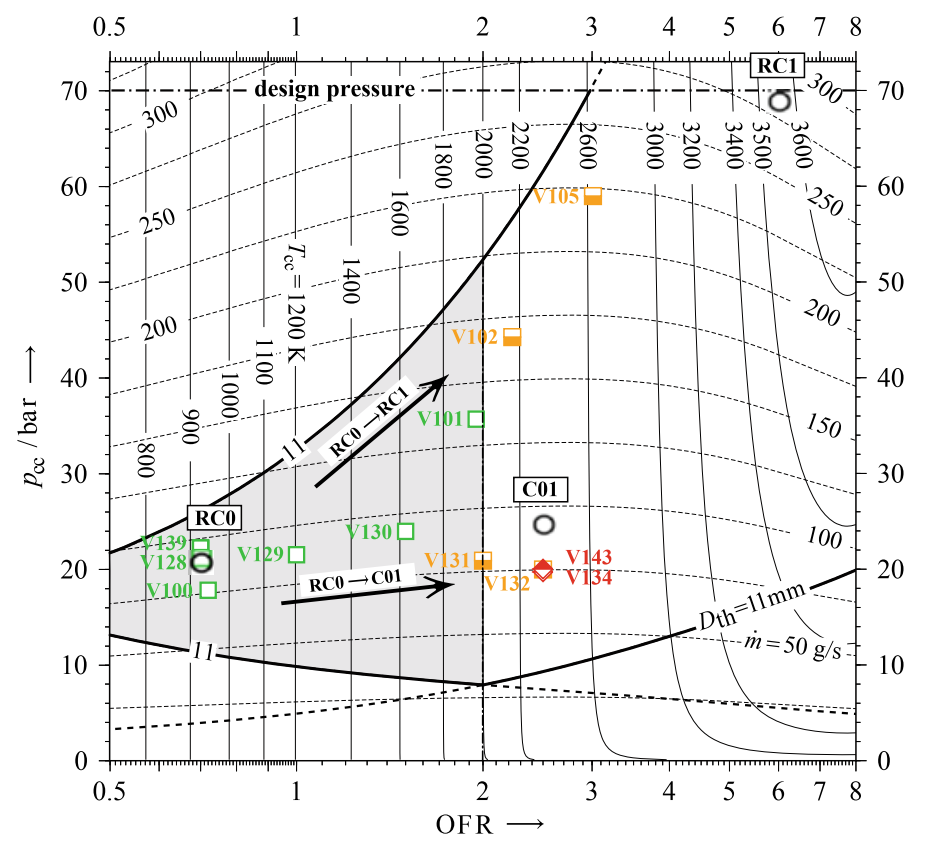

Fig. 7 Operating range of the GH2/GO2 facility limited to the design of the HOC1 combustor; labels V100-V143 show the conducted tests for the characterization of the facility under reference condition RC0 and several off-design conditions

within the external wind tunnel flow. There, it was supplied with the propulsive gas via its support structure. The internal flow was generated by expansion through the model's thrust nozzle at the base of the generic rocket. Reference [14] shows our first approach of visualizing the flow topology for both, the cold plume and GH2/GO2 hot plume test cases in combination with ambient flow. For that, a Schlieren optics setup with high-speed imaging equipment within the topological region given in Fig. 8 was used. The goal was to analyze the Schlieren recordings with respect to their spectral content in order to identify and compare dominant frequencies, their intensities, and the local distribution in the wake between the different test cases.

\subsection{GH2/GO2 Wind Tunnel Model}

The wind tunnel model is located on top of the central support structure, which is held within a cylindrical duct upstream of the convergent subsonic wind tunnel nozzle via eight tubes (Fig. 9). The tubes are used to supply the model with combustion gases $(2 \mathrm{xGH} 2,2 \mathrm{xGO} 2)$ or high-pressure air, cabling for sensors and ignition, and optional coolant mass flow. The detailed internal and external dimensions of the 
Fig. 8 Flow topology of the subsonic wake behind an axisymmetric backward-facing step with supersonic exhaust jet

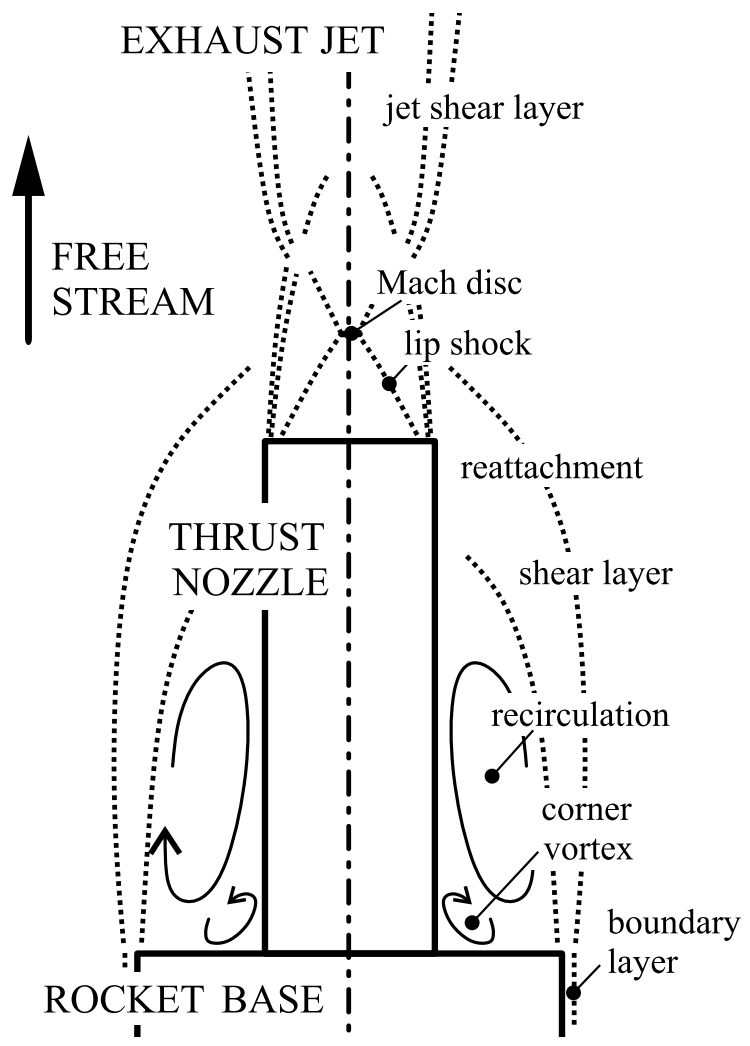

wind tunnel model extension are given in [14]. The axisymmetric backward-facing step is a generic representation of the Ariane 5 main stage afterbody with respect to the ratios of $L / D$ and $d / D$ on a scale of $1 / 80$. The outer dimensions are equal to previous investigations by Saile et al. [17, 20, 21], although the model was remade due to the functional requirements for hot gas testing. The inner geometry of the thrust chamber and single element shear flow injector was designed and investigated in previous work [19]. The thrust chamber and nozzle extension are made of oxygenfree high thermal conductivity $(O F H C)$ copper, the injector part is made by additive manufacturing of an Inconel 718 alloy with a maximum temperature rating of $1020 \mathrm{~K}$ to prevent hydrogen environment embrittlement.

\subsection{Test Program and Test Conditions}

References [13, 14] compare four main test cases at the critical ambient flow Mach number of 0.8 to investigate the main characteristics of the base flow dynamics and topological features with regard to the influence of a hot exhaust jet. First, the cold 
Fig. 9 Wind tunnel model with combustion chamber for plume interaction testing mounted on an upstream center-body

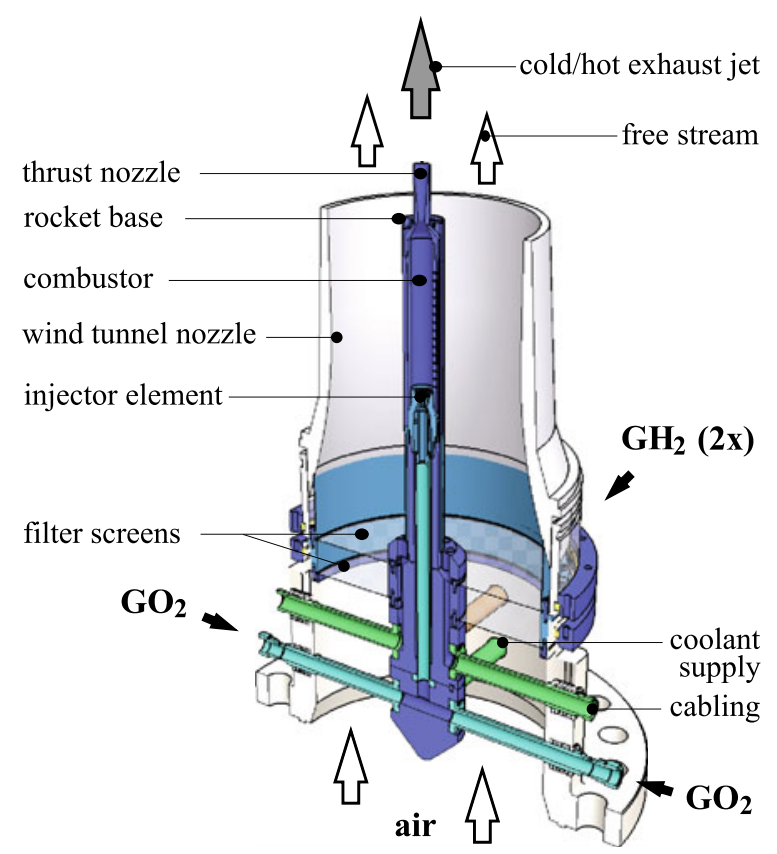

exhaust jet is measured without ambient flow and the wake flow is measured without an active exhaust jet. Then, a cold exhaust jet is added, similarly as in preceding investigations by Saile et al. [17, 21]. Finally, the analysis proceeds to a test case with hot exhaust jet. The approach is to consequently keep the ambient flow and chamber conditions constant through all tests, as far as possible. The test conditions are depictured in Fig. 10 and are given in more detail in [13, 14]. Figure 10 also shows the comparability of the test cases within the evaluation time window $t_{\mathrm{eval}}$.

\subsection{Wind Tunnel Test Results}

To compare the findings from the spectral analysis, dominant frequencies of specific types of flow features similar to, or included in, the flows under investigation, were estimated in [14]. They were categorized in the acoustic and spatial modes of the model's pressure chamber, modes of the dynamic motion of the rocket wake flow, and acoustic phenomena from the jet dynamics. Detailed information on how the frequencies were estimated can be found in [14]. In the following section, it is shown that in case of cold jet interaction, where the swinging motion of the ambient shear flow matched the jet screeching frequency on the one hand and the $2 \mathrm{~L}$ mode of the pressure chamber on the other hand, large fluctuations arose within the wake flow region. In contrast, this was not the case for the hot jet interaction experiments. 
Fig. 10 Internal and external flow properties for all test cases in time; constant flow conditions are maintained within the evaluation time window $t_{\text {eval }}=[18.0 ; 20.0] \mathrm{s}$

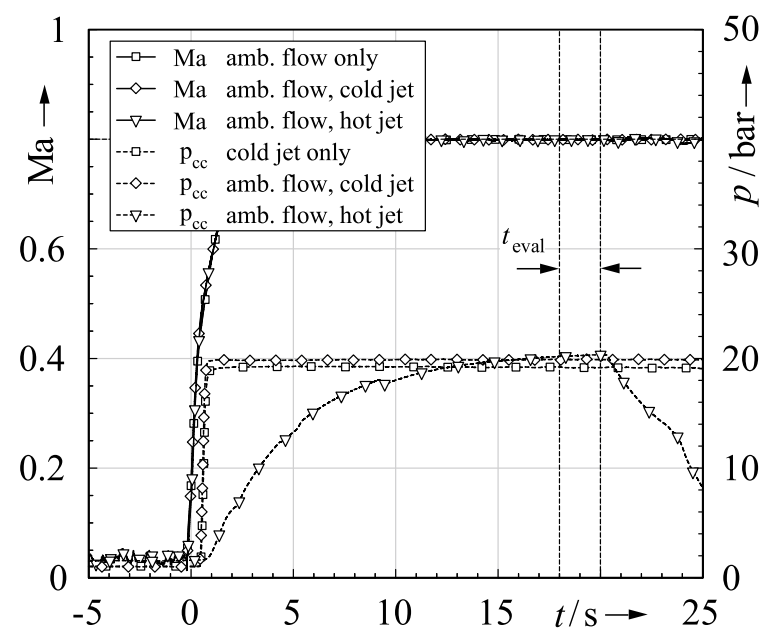

Therefore, the analysis of the results focused on the causalities and evaluates the different influences on the wake flow dynamics.

\subsubsection{Cold Plume Interaction}

\section{Temporal Characterization}

Figure 11 shows the power spectra of the High-speed Schlieren (HSS) intensity fluctuations for the ambient flow cases without jet and with cold jet. These were analyzed in combination with the power spectra of the dynamic total pressure measurements inside the model pressure chamber. The amplitude spectrum of the HSS image intensity fluctuations shows three major peaks for the ambient flow case without jet. According to [13, 14], the peaks at $700 \mathrm{~Hz}$ and around $1330 \mathrm{~Hz}$ can be assigned to the cross-flapping and swinging motion frequencies of the shear layer, estimated as $f_{\mathrm{cf}}=753 \mathrm{~Hz}\left(\mathrm{Sr}_{D}=0.2\right)$ and $f_{\mathrm{sw}}=1318 \mathrm{~Hz}\left(\operatorname{Sr}_{D}=0.35\right)$.

In case of ambient flow with cold jet, the pressure chamber fluctuations (Fig. 11, dashed line) are amplified for certain frequencies, compared to the ambient flow without jet. In particular, this is true for the band around $1330 \mathrm{~Hz}$, where the swinging motion is observed for the ambient flow without jet, as well as for $1235 \mathrm{~Hz}$, which is close to the estimated jet screeching frequency $f_{\mathrm{sc}}=1247 \mathrm{~Hz}$. This strong congruency with the estimated characteristic frequencies of the wake flow and jet dynamics yields to the hypothesis, that flow-flow interaction, leading to an amplification of certain flow features might appear. This hypothesis is further supported by an extreme peak in the HSS power spectrum for cold jet interaction at around $1330 \mathrm{~Hz}$, which corresponds to the swinging motion frequency as well as the $2 \mathrm{~L}$ chamber mode. This gives rise to the assumption that a strong coupling exists between the broadband chamber pressure oscillations around $1330 \mathrm{~Hz}$, including the $2 \mathrm{~L}$ mode, 
Fig. 11 HSS power spectra of ambient flow with cold jet; comparison with chamber pressure spectra and the estimated screeching frequency

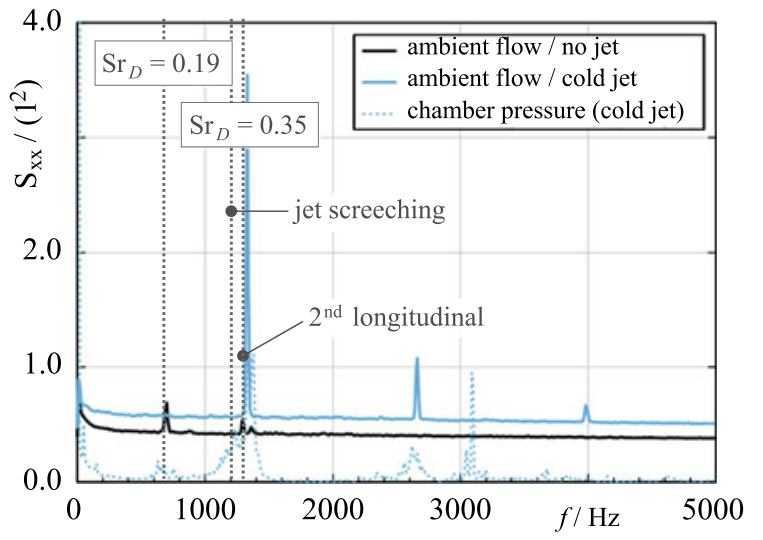

the jet screeching, and the swinging motion of the shear layer. What is unclear at this point is to which extent the three different frequencies contribute to the observed amplification.

\section{Spatial Characterization}

In addition to the temporal features of the flow field, Fig. 12 gives an overview on the spatial characteristics, or eigenmodes, of the flow field's motion. Figures 12a and $\mathrm{b}$ show that the peaks in the HSS power spectrum are actually related to spatial distributions according to the known cross-flapping and swinging motion of the ambient shear layer without jet interaction. Adding the cold exhaust jet leads to a strong amplification of the swinging motion, shown in Fig. 12c, as previously expected from the HSS power spectrum (Fig. 11). It is evident, that most of the fluctuation energy is concentrated in circular structures, emanating from the base shoulder and continuing within the shear layer down to the far wake.

\subsubsection{Hot Plume Interaction}

\section{Temporal Characterization}

The power spectrum of the HSS intensity fluctuations from the hot jet case (Fig. 13 shows a slightly higher mean level compared to the cold jet case. However, the amplitude level strongly depends on the optical setup and the dynamic range of the global density. Since the hot jet density significantly deviates from the cold jet density by approximately one order of magnitude, this effect might be related to the generally higher density gradients in the field. Further, the spectrum does not reveal increased peaks referred to chamber oscillations. This means that no distinct excitation of the near-wake flow takes place due to fluctuations in the chamber. Nevertheless, peaks can be detected at the same characteristic frequencies as found for the ambient flow without jet $(700,1290$, and $1360 \mathrm{~Hz})$. Therefore, the flow field 
a) no jet, $\mathrm{Sr}_{D}=0.19$

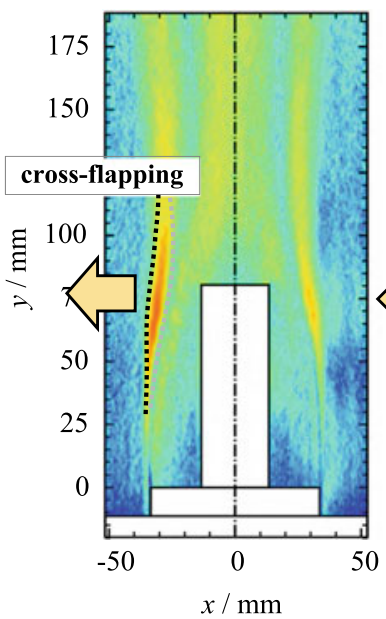

b) no jet, $\mathrm{Sr}_{D}=0.35$

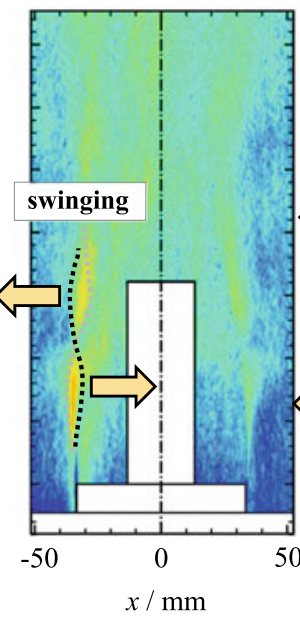

c) cold jet, $\mathrm{Sr}_{D}=0.35$

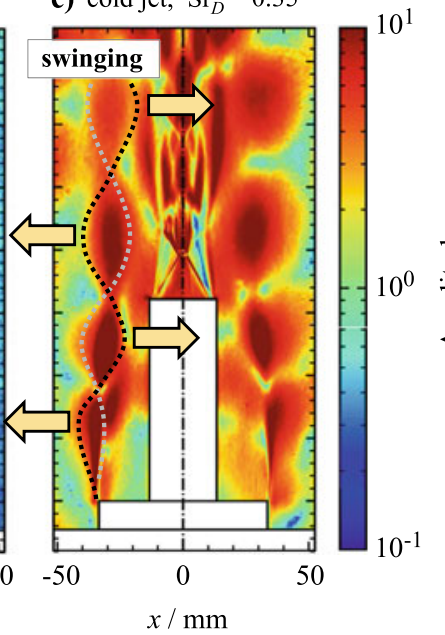

Fig. 12 Amplitude distribution of the power spectrum for ambient flow without jet and with cold jet; a ambient flow without jet at $\mathrm{Sr}_{D}=0.19$ (cross-flapping motion); $\mathbf{b}$ ambient flow without jet at $\operatorname{Sr}_{D}=0.35$ (swinging motion); $\mathbf{c}$ ambient flow with cold jet at $\operatorname{Sr}_{D}=0.35$ (swinging motion)

Fig. 13 HSS power spectra of ambient flow with hot jet; comparison with chamber pressure spectra and the estimated screeching frequency

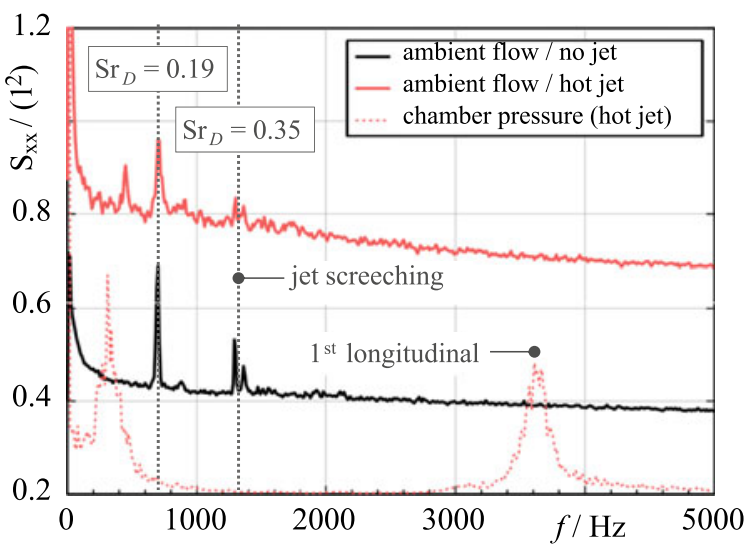

is dominated by the well-known near-wake flow dynamics such as the cross-flapping and swinging motion. However, the previously found strong excitation mechanisms and presumable coupling phenomena cannot be detected in this case.

\section{Spatial Characterization}

As expected from the average HSS power spectra, the ambient flow case with hot jet interaction behaves similarly to the ambient flow without jet regarding the frequencies of the cross-flapping and swinging motion. In Fig. 14, they are plotted in their most intensified bands, which are $710 \mathrm{~Hz}$ for the cross-flapping motion (Fig. 14a) and $1300 \mathrm{~Hz}$ for the swinging motion (Fig. 14b), which correspond to $\operatorname{Sr}_{D}=0.2$ 


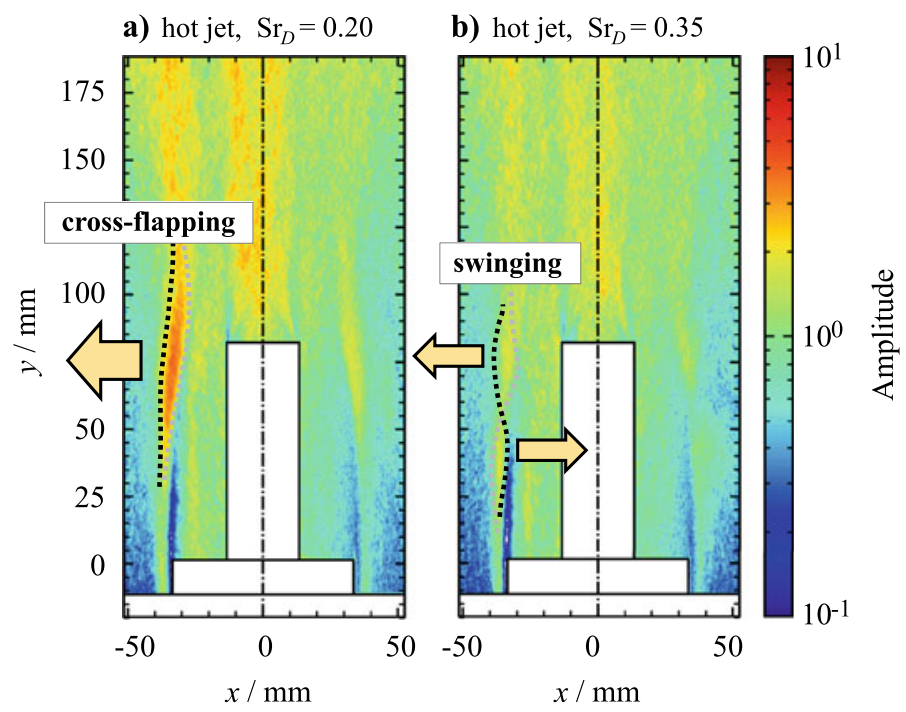

Fig. 14 Amplitude distribution of the power spectrum for ambient flow with hot jet; $\mathbf{a} \operatorname{Sr}_{D}=0.20$ (cross-flapping motion); $\mathbf{b ~} \mathrm{Sr}_{D}=0.35$ (swinging motion)

and $\operatorname{Sr}_{D}=0.35$. Compared to the ambient flow without jet, the mean amplitude is increased in the whole interacting flow regime. In particular, this is true inside the jet and in the far wake of the bluff body, where the shear layers are interacting strongly. In contrast to the cold gas interaction, no amplification of local distinct flow features is visible in this case.

\section{Conclusions}

Since June 2017, a new supply facility for gaseous hydrogen-oxygen-combustion supplements the Vertical Wind Tunnel Facility (VMK) of the German Aerospace Center (DLR) in Cologne to the Hot Plume Testing Facility (HPTF), which was designed and manufactured as part of SFB/TRR40, sub-project B1, to be facilitated for rocket plume interaction experiments with hot exhaust jets and realistic composition [10]. It was put into operation using the rocket combustor model (HOC1), which was designed as a prospective duplicate of later wind tunnel model combustors, in order to characterize the facility operation under relevant operating conditions, and to prove feasibility of future wind tunnel test campaigns.

\section{Characterization of HPTF}

The characterization of HPTF was done in order to demonstrate the suitability of its concept for future wind tunnel experiments [11]. The tests were conducted under the requirements of the following test campaigns at reference condition RC0 and by 
varying flow parameters towards higher operating conditions to generate a suitable operating range. The current design state led to an operating range of mixture ratios $0.6<$ OFR $<2.0$ at a maximum mass flow rate $\dot{m}<150 \mathrm{~g} / \mathrm{s}$. For the model setup within SFB/TRR40, this is equivalent to a total chamber pressure $p_{\mathrm{cc}}<40$ bar with stagnation temperature $T_{\mathrm{cc}}<2000 \mathrm{~K}$. Possible measures to extend the operating range beyond those limits are discussed in [11]. During the characterization test campaign, control precision, repeatability, and combustion stability were proven for the newly established operating range with typical run times of 30-40 s at RC0.

\section{Cold and Hot Plume Interaction}

Spectral analyzes of the wake flows behind a generic rocket launcher geometry at ambient flow Mach number 0.8, interacting with a supersonic exhaust jet by means of HSS imaging revealed large differences in the fluctuating density gradient fields between flow configurations with cold and hot exhaust jets [13, 14]. Analytical estimations of the acoustic properties of the pressure chamber, the characteristic wake flow modes, and the dynamic features of the supersonic jet were compared with spectral analyzes of the HSS intensity fluctuations of the near-wake and total chamber pressure measurements. Test cases of ambient flow without jet and ambient flow with hot jet showed the typical wake flow modes, which were in good agreement with the estimated non-dimensional frequencies from literature [28]. The ambient flow with cold exhaust jet revealed resonance in the spatially averaged spectrum of the HSS intensity fluctuations at $\mathrm{Sr}_{D}=0.35$, which is traced to the swinging motion of the ambient shear layer. It is assumed that a strong coupling exists between the ambient shear layer and the fluctuating jet shear layer.

The strong differences in the receptivity of the far wake on incoming disturbances from either cold or hot exhaust jets could not be fully explained in the course of the SFB/TRR40. However, its relevance for the design of future rocket components should be clarified by further investigations. Various measures for such an endeavor are suggested in more detail in [13, 14].

Acknowledgements Financial support has been provided by the German Research Foundation (Deutsche Forschungsgemeinschaft-DFG) in the framework of the Sonderforschungsbereich Transregio 40. The support of the technical staff during the work at the Supersonic and Hypersonic Technology Department in Cologne is highly appreciated.

\section{References}

1. Adams, N., Stemmer, C., Radespiel, R., Sattelmayer, T., Schröder, W., Weigand, B.: SFBTransregio 40: Technologische Grundlagen für den Entwurf thermisch und mechanisch hochbelasteter Komponenten zukünftiger Raumtransportsysteme-Motivation und Struktur. In: 60. Deutscher Luft- und Raumfahrtkongress. Bremen, Germany (2011)

2. Blomshield, F.S.: Lessons learned in solid Rocket combustion instability. In: 43rd AIAA/ASME/SAE/ASEE Joint Propulsion Conference \& Exhibit. Cincinnati, Ohio (2007)

3. David, S., Radulovic, S.: Prediction of buffet loads on the Ariane 5 afterbody. In: 6th International Symposium on Launcher Technologies. Munich, Germany (2005) 
4. Deck, S., Thorigny, P.: Unsteadiness of an axisymmetric separating-reattaching flow: numerical investigation. Phys. Fluids 19(065103), 1-20 (2007)

5. Deprés, D., Reijasse, P., Dussauge, J.P.: Analysis of unsteadiness in afterbody transonic flows. AIAA J. 42(12), 2541-2550 (2004)

6. van Gent, P., Payanda, Q., Brust, S., van Oudheusden, B.W., Schrijer, F.: Experimental study of the effects of exhaust plume and nozzle length on transonic and supersonic axisymmetric base flows. In: 7th European Conference for Aeronautics and Space Sciences (EUCASS). Milan, Italy (2017)

7. Haidn, O.J., Adams, N.A., Sattelmlayer, T., Stemmer, C., Radespiel, R., Schröder, W., Weigand, B.: Fundamental technologies for the development of future space transportsystem components under high thermal and mechanical loads. In: 2018 Joint Propulsion Conference. Cincinnati, Ohio (2018). AIAA 2018-4466

8. Hannemann, K., Lüdecke, H., Pallegoix, J.F., Ollivier, A., Lambaré, H., Maseland, H., Geurts, E., Frey, M., Deck, S., Schrijer, F., Scarano, F., Schwane, R.: Launch vehicle base buffetingrecent experimental and numerical investigations. In: 7th European Symposium on Aerothermodynamics. Brugge, Belgium (2011)

9. Kirchheck, D., Gülhan, A.: GH2/GO2 supply facility for hot plume testing in the vertical test section Cologne (VMK). In: Sonderforschungsbereich/Transregio 40-Annual Report (2016)

10. Kirchheck, D., Gülhan, A.: Launch of the $\mathrm{GH} 2 / \mathrm{GO} 2$ supply facility for hot plume testing at DLR Cologne. In: Sonderforschungsbereich/Transregio 40-Annual Report (2017)

11. Kirchheck, D., Gülhan, A.: Characterization of a GH2/GO2 combustor for hot plume wind tunnel testing. In: Sonderforschungsbereich/Transregio 40-Annual Report (2018)

12. Kirchheck, D., Gülhan, A.: Interaktionsteststand für realistische Raketentreibstrahlen mit umströmender Atmosphäre. In: Deutscher Luft- und Raumfahrtkongress (DLRK). Munich, Germany (2017)

13. Kirchheck, D., Saile, D., Gülhan, A.: Spectral analysis of generic rocket wake flows with cold and hot exhaust jets. In: Sonderforschungsbereich/Transregio 40—Annual Report (2019)

14. Kirchheck, D., Saile, D., Gülhan, A.: Spectral analysis of rocket wake flow-jet interaction by means of high-speed Schlieren imaging. In: 8th European Conference for Aeronautics andSpace Sciences (EUCASS). Madrid, Spain (2019)

15. Marshall, W.M., Pal, S., Woodward, R.D., Santoro, R.J.: Benchmark wall heat flux data for a GO2/GH2 single element combustor. In: 41st AIAA/ASME/SAE/ASEE Joint Propulsion Conference \& Exhibit. Tucson, Arizona (2005)

16. Radespiel, R., Glatzer, C., Hannemann, K., Saile, D., Scharnowski, S., Windte, J., Wolf, C., You, Y.: SFB-Transregio 40: Heckströmungen. In: 60. Deutscher Luft- und Raumfahrtkongress. Bremen, Germany (2011)

17. Saile, D.: Experimental analysis on near-wake flows of space transportation systems. Ph.D. thesis, Rheinisch-Westfälische Technische Hochschule (RWTH) Aachen (2019)

18. Saile, D., Kirchheck, D., Gülhan, A., Banuti, D.: Design of a hot plume interaction facility at DLR Cologne. In: 8th European Symposium on Aerothermodynamics for Space Vehicles (ATD). Lisbon, Portugal (2015)

19. Saile, D., Kirchheck, D., Gülhan, A., Serhan, C., Hannemann, V.: Design of a GH2/GOX combustion chamber for the hot plume interaction experiments at DLR Cologne. In: 8th European Symposium on Aerothermodynamics for Space Vehicles (ATD). Lisbon, Portugal (2015)

20. Saile, D., Kühl, V., Gülhan, A.: On the subsonic near-wake of a space launcher configuration with exhaust jet. Exp. Fluids 60(165), 17 (2019). https://doi.org/10.1007/s00348-019-2801-7

21. Saile, D., Kühl, V., Gülhan, A.: On the subsonic near-wake of a space launcher configuration without jet. Exp. Fluids 60(4), 50 (2019). https://doi.org/10.1007/s00348-019-2690-9

22. Saile, D., Kühl, V., Gülhan, A.: On subsonic near-wake flows of various base geometries. In: 13th International Symposium on Particle Image Velocimetry (ISPIV). Munich, Germany (2019)

23. Schoones, M., Bannink, W.: Base Flow and Exhaust Plume Interaction. Part 1: Experimental Study. Delft University Press (1998) 
24. Schoones, M., Houtman, E.: Base Flow and Exhaust Plume Interaction. Part 2: Computational Study. Delft University Press (1998)

25. Schreyer, A.M., Stephan, S., Radespiel, R.: Characterization of the supersonic wake of a generic space launcher. CEAS Space J. 9(1), 97-110 (2017)

26. Schwane, R.: Numerical prediction and experimental validation of unsteady loads on ARIANE5 and VEGA. J. Spacecraft Rockets 52(1), (2015)

27. Statnikov, V., Bolgar, I., Scharnowski, S., Meinke, M., Kähler, C.J., Schröder, W.: Analysis of characteristic wake flow modes on a generic transonic backward-facing step configuration. Eur. J. Mech. B/Fluids 59, 124-134 (2016)

28. Statnikov, V., Meinke, M., Schröder, W.: Reduced-order analysis of buffet flow of space launchers. J. Fluid Mech. 815, 1-25 (2017)

29. Stephan, S., Radespiel, R.: Propulsive jet simulation with air and helium in launcher wake flows. CEAS Space J. 9(2), 195-209 (2017)

30. Sutton George, P., Biblarz, O.: Rocket Propulsion Elements. Wiley (2001)

31. Weiss, P.E., Deck, S., Robinet, J.C., Sagaut, P.: On the dynamics of axisymmetric turbulent separating/reattaching flows. Phys. Fluids 21(7), 1-8 (2009)

Open Access This chapter is licensed under the terms of the Creative Commons Attribution 4.0 International License (http://creativecommons.org/licenses/by/4.0/), which permits use, sharing, adaptation, distribution and reproduction in any medium or format, as long as you give appropriate credit to the original author(s) and the source, provide a link to the Creative Commons license and indicate if changes were made.

The images or other third party material in this chapter are included in the chapter's Creative Commons license, unless indicated otherwise in a credit line to the material. If material is not included in the chapter's Creative Commons license and your intended use is not permitted by statutory regulation or exceeds the permitted use, you will need to obtain permission directly from the copyright holder. 